\title{
Effect of high somatic cell counts on reproductive performance of Chilean dairy cattle
}

\author{
P. J. Pinedo, ${ }^{*} †$ P. Melendez, ${ }^{*} \ddagger$ J. A. Villagomez-Cortes, ${ }^{*}$ and C. A. Risco*1 \\ ${ }^{*}$ College of Veterinary Medicine, University of Florida, PO Box 100136, Gainesville 32610-0136 \\ †Department of Animal Sciences, University of Florida, PO Box 110910, Gainesville 32611-0910 \\ $\ddagger$ College of Veterinary Medicine, University of Santo Tomas, Av. Limonares 190, Viña del Mar, Chile
}

\section{ABSTRACT}

The objectives were to evaluate the effect of high linear somatic cell counts (LNSCC $\geq 4.5$ ) during early lactation on reproductive performance and to estimate their association with the risk of abortion in a population of central-southern Chilean dairy cattle. The analysis included records from a population of 157 farms and considered 1,127,405 test-day records including 101,944 lactations that began between 1997 and 2006 . After data edits, the analyses of calving to first service and calving to conception intervals consisted of 88,633 and 70,877 lactations, respectively. Once controlling for significant variables, time to first breeding was $21.8 \mathrm{~d}$ longer in cows with at least 1 high LNSCC before the first breeding compared with controls. Cows with at least 1 high LNSCC before the fertile breeding had an increment in time to conception of $48.7 \mathrm{~d}$ and required, on average, 0.49 more services to conceive. The odds of conception at first service in cows with a high LNSCC within $30 \mathrm{~d}$ before [after] breeding were 0.85 (0.81 to $0.89 ; 95 \%$ confidence interval ) [0.82 (0.78 to $0.87 ; 95 \%$ confidence interval)] times the odds of conception for cows without a high LNSCC during that period. The Cox proportional hazard model indicated that after correction by calving year, lactation number, and milk yield standardized to $305 \mathrm{~d}$, the risk of pregnancy decreased by $44 \%$ if a high LNSCC occurred before breeding. Cows registering a high LNSCC during the first 90 $\mathrm{d}$ of gestation had an increased risk of abortion, being 1.22 (1.07 to $1.35 ; 95 \%$ confidence interval) times more likely to abort than nonaffected cows. It is concluded that subclinical mastitis, measured as LNSCC $\geq 4.5$, had a significant effect on reproductive performance in Chilean dairy cattle.

Key words: fertility, somatic cell, Chile, dairy

Received October 6, 2008

Accepted November 25, 2008.

${ }^{1}$ Corresponding author: RiscoC@vetmed.ufl.edu

\section{INTRODUCTION}

Bovine mastitis is defined as an inflammation of the mammary gland due to infectious or noninfectious causes (Bradley, 2002) and continues to be an economically important disease of dairy cattle (Kossaibati and Esslemont, 1997; Bar et al., 2007). Economic losses related to clinical mastitis were described and include lower milk production, replacement, and treatment costs, among others (Miller et al., 1993; Rajala-Schultz et al., 1999). In addition, clinical mastitis affects reproductive performance, resulting in an increase in the number of days to first service, days open, and services per conception (Moore et al., 1991; Barker et al., 1998), together with a higher risk of abortion (Risco et al., 1999; Santos et al., 2004).

Clinical mastitis caused by gram-negative bacteria may adversely affect the reproductive cycle of the dairy cow by altering the interestrus interval and by causing abortion through the release of inflammatory mediators (Moore et al., 1991). The activation of inflammatory or immune responses external to the reproductive tract by release of LPS, proteoglycans, and other molecules of bacterial origin can lead to embryonic mortality. Effects of these inflammatory mediators include alteration of LH release and FSH activity, which can alter oocyte development, estrous cycle, and embryonic function (Hansen et al., 2004). Gram-positive bacteria causing clinical mastitis may be associated with embryonic losses in dairy cows by stimulating the release of inflammatory mediators and pyrexia (Barker et al., 1998). In contrast, endotoxin (LPS) from gram-negative bacteria increased serum $\mathrm{PGF}_{2 \alpha}$ levels (Giri et al., 1984, 1990; Jackson et al., 1990) and, through its luteolytic action, altered the estrous cycle or caused abortion in cows (Gilbert et al., 1990).

Subclinical mastitis, defined as the presence of the same pathogen in at least 2 consecutive milk samples, resulted in lower reproductive performance of lactating cows, comparable to cows with clinical mastitis (Schrick et al., 2001). Furthermore, a negative effect of a linear SCC $\geq 4.5$ on embryo survival was reported 
(Moore et al., 2005). Still, a paucity of research exists on the magnitude of the effect of subclinical mastitis, identified by an elevated linear SCC, on reproductive performance of lactating dairy cows.

The central hypothesis was that subclinical mastitis, diagnosed by an elevated SCC, affects fertility and reproductive performance of dairy cattle through a reduction in conception and an increase on the risk of abortion.

Therefore, the objectives were 1) to evaluate the effect of high SCC during early lactation on reproductive performance, and 2) to determine the association between a high linear SCC (LNSCC) and the risk of abortion in a population of central-southern Chilean dairy cattle.

\section{MATERIALS AND METHODS}

\section{Dairy Farms and Management}

This was a retrospective study considering dairy farms from the central-south area of Chile. The area is located between $36^{\circ} 00^{\prime}$ and $38^{\circ} 30^{\prime}$ south and between $71^{\circ} 00^{\prime}$ west and the Pacific Ocean. Climate is temperate with winter rainfall $(1,380 \mathrm{~mm} / \mathrm{yr})$ and temperatures that range from $0^{\circ} \mathrm{C}$ in winter to $32^{\circ} \mathrm{C}$ in summer (Instituto Geográfico Militar, 2006). The central-south area of Chile is a typical agricultural region and represents $30 \%$ of the total cattle population of the country.

Dairy farms consisted of Holstein cattle (90\%) and crossbred Black-Pied $\times$ Holstein $(10 \%)$. Housing was dry lot (40\%), freestalls (40\%), grazing (10\%), and mixed systems (10\%). Feeding systems were TMRbased consisting of corn silage, alfalfa hay, and concentrates $(50 \%)$, top-dressed concentrate, corn silage, and green chop/hay alfalfa (30\%), grazing (10\%), and mixed systems (10\%). Reproductive management consisted of AI based on detection of estrus (80\%), natural service (10\%), and mixed AI and natural service systems (10\%). In herds using natural service (small herds), bulls were housed in individual pens separated from cows. Cows were hand mated with bulls after detected estrus; therefore, date of breeding was known. Milking frequency was 3 times $(35 \%)$ or 2 times daily (65\%), using standard commercial automated milking machines.

\section{Study Design}

This retrospective cohort study analyzed data collected by a government certified recording system organization (Insecabio Ltda., Los Angeles, Chile) that had monitored (monthly) a population of approximately 12,000 Holstein cattle distributed in 187 herds during the last $15 \mathrm{yr}$.
The study used records from a population of 157 farms and considered 1,127,405 test-day records including 101,944 lactations that began between 1997 and 2006. Data were obtained by certified technicians during monthly visits to the farms. Technicians recorded individual milk production during a complete day milking cycle (2 or 3 times daily milking), and collected individual milk samples from every cow during the milking. Samples were preserved by addition of potassium dichromate and analyzed in a Combifoss 5000 (Foss, Hillerød, Denmark) device comprising a Fossomatic 5000 somatic cell counter (based on the flow cytometry principle) and a MilkoScan 4000 component for MUN, fat, and protein analysis. Samples were analyzed for fat (\%), protein (\%), SCC (cells/mL), and MUN (mg/dL) contents.

Information collected on-farm consisted of the herd unique code identification, test-day date, number of milking cows and distribution per number of lactations, and average milk production of the herd at the day of sampling. Cow individual information consisted of milk production during the recording day, milk components (SCC, MUN, fat, and protein), and biological and management events such as calving date, breeding date and number, pregnancy diagnosis, abortion, date of dry off, culling date, and death date, among others.

The study was divided in 2 phases. Objective 1 evaluated the effect of high SCC occurring during early lactation on the calving to first service interval (CFSI), the calving to conception interval (CCI), and the number of services per conception (SC). This phase considered the analysis of the effect of high SCC on the outcome (conception) of first breedings occurring in a concurrent period. Objective 2 examined the association between the occurrence of high LNSCC during the first third of pregnancy (1 to $90 \mathrm{~d}$ post-conception) and an increased risk of abortion.

\section{Outcome Variables and Statistical Analysis}

Reproductive performance was evaluated by the following outcome variables: 1) CFSI, defined as the number of days between parturition and the subsequent first breeding; 2) CCI, defined as the number of days between parturition and the breeding that resulted in pregnancy; 3) SC, defined as the number of breedings that a cow required to conceive; 4) conception at first service (CFS), defined as the result of a first breeding after calving (pregnancy or not); and 5) abortion occurrence, defined as the loss of the conceptus after $45 \mathrm{~d}$ of gestation until $270 \mathrm{~d}$ of gestation, taking place after pregnancy has been diagnosed.

For objective 1, conception was the outcome considered for a successful breeding if a subsequent pregnancy 
was diagnosed by the farm veterinarian (palpation per rectum of the uterus and its contents or use of ultrasound). Failure to conceive was considered if the cow was determined to be nonpregnant by the farm veterinarian or if a subsequent breeding was reported after 17 to $24 \mathrm{~d}$ post-breeding. In objective 2, abortion was considered as an outcome if pregnancy loss was reported.

For the analysis, SCC were natural log-transformed to a $\log$ linear score (LNSCC). The explanatory variables of interest for objective 1 were LNSCC between calving and first service, LNSCC between calving and a fertile service, and LNSCC in the proximity of the date of first breedings. The LNSCC were classified as low (score $<4.5$ ) or high (score $\geq 4.5$; Moore et al., 2005). For a high LNSCC close to the date of a first breeding, 3 variables were considered in the analysis: 1 ) closest LNSCC within the previous $30 \mathrm{~d}$ of the breeding date; 2) closest LNSCC within $30 \mathrm{~d}$ after the breeding date; or 3) LNSCC before, after, or concurrent with the breeding date. Given that the interval between 2 consecutive visits to each farm (test-days) was $30 \pm 5$ $\mathrm{d}$, the selected range of $30 \mathrm{~d}$ was appropriate for this analysis.

For objective 2, the main explanatory variable was occurrence (yes/no) of a high LNSCC (score $\geq 4.5$ ) during the first $90 \mathrm{~d}$ of gestation.

Other explanatory independent variables considered in the analysis were parity (1, 2 or more); calving season (summer, fall, winter, spring); year of calving (1997 to 2006); milk production standardized to $305 \mathrm{~d}$ based on an approved methodology (Keown et al., 1986) and categorized as low, medium, and high; herd size (categorized as small, medium, and large); and herd production level (categorized as low, medium, and high).

Definitions for categorized variables were seasons: summer $=$ December 1 to February 28/29; autumn = March 1 to May 31; winter = June 1 to August 31; and spring $=$ September 1 to November 30 ; herd size: small $=<77$ cows; medium $=77$ to 140 cows; and large $=$ $>140$ cows (Melendez and Pinedo, 2007); milk yield standardized to $305 \mathrm{~d}$ : low $=<6,000 \mathrm{~kg}$; medium $=$ 6,000 to $8,000 \mathrm{~kg}$; high $=>8,000 \mathrm{~kg}$; herd milk yield standardized to 305-d mature equivalent: low $=<7,100$ $\mathrm{kg}$; medium $=7,100$ to $8,950 \mathrm{~kg} ;$ high $=>8,950 \mathrm{~kg}$; and lactation number: $1=$ primiparous; $2=$ multiparous. Biologically relevant 2-way interactions were included in preliminary models, but they were removed when not significant.

Calving to first service interval, CCI, and SC were evaluated using the GLM methodology (PROC GLM and PROC REG; SAS Inst. Inc., Cary, NC). Models for conception risk at first service and abortion occurrence were evaluated by logistic regression (PROC LOGIS-
TIC; SAS Inst. Inc.) through a backward elimination procedure.

Survival analysis, including a Cox proportional regression model and survival curves were estimated to evaluate the risk of pregnancy over time for cows with high LNSCC during early lactation versus control cows (PHREG procedure; SAS Inst.). For the final models variables were considered significant when $P \leq 0.05$.

\section{RESULTS AND DISCUSSION}

\section{Reproductive Indices}

Raw means for CFSI, CCI, and the SC during the period 1997 to 2006 were $92.8 \mathrm{~d}, 136 \mathrm{~d}$, and 1.84, respectively. Results for linear regression of proposed variables on these traits are in Table 1 . The analysis included 88,633 and 70,877 lactations in which CFSI and CCI were available, respectively. Least squares means for CFSI were $86.1 \mathrm{~d}$ for control cows and 107.9 $\mathrm{d}$ for cows with a high LNSCC $(\geq 4.5)$ before CFSI. Conversely, least squares means for CCI were $120.6 \mathrm{~d}$ for control cows and $169.3 \mathrm{~d}$ for cows with a high LNSCC. Consequently, the regression coefficient for our main explanatory variable in the analysis of CFSI indicated that, after controlling for significant variables, cows with at least 1 high LNSCC $(\geq 4.5)$ before CFSI increased this index by $21.8 \mathrm{~d}(P<0.0001)$. Cows with at least 1 high LNSCC $(\geq 4.5)$ before CCI increased the time to conception by $48.7 \mathrm{~d}(P<0.0001)$. Similarly, this group of cows required 0.49 more SC. These values support the results of Rekik et al. (2008) who reported an increase in CFSI and CCI of 1.3 to $2.0 \mathrm{~d}$ for each unit increase in test-day SCS. Miller et al. (2001) reported that CFSI was significantly greater for cows with clinical mastitis before first service than for nonaffected cows (94 vs. $71 \mathrm{~d}$ ). A larger effect was observed on days from CCI in which cows with clinical mastitis after first service had greater CCI (137 d) than control cows $(93 \mathrm{~d})$. Consequently, SC increased from 1.7 to 2.9 for cows affected by mastitis before conception. In another study, Barker et al. (1998) indicated that CFSI was increased by $22.6 \mathrm{~d}$ in cows with clinical mastitis before first service compared with control cows. Days to conception were $44.5 \mathrm{~d}$ greater in affected cows (high LNSCC), and SC were 1.6 and 2.9 for control cows vs. affected animals, respectively. Similarly, Schrick et al. (1999) reported an increase in $7.9 \mathrm{~d}, 20.8 \mathrm{~d}$, and 0.4 units in CFS, CCI, and SC for cows affected with mastitis before first service compared with unaffected cows. The increase was $58.1 \mathrm{~d}$ and 1.5 units in CCI and $\mathrm{SC}$, for cows that experienced mastitis between first $\mathrm{AI}$ and establishment of pregnancy compared with uninfected cows. These authors reported a similar effect 
Table 1. Regression coefficients of variables that affected days to first service, calving to conception interval, and services per conception in central-southern Holstein Chilean cattle (only significant effects are included; $P \leq 0.05)$

\begin{tabular}{lccc}
\hline Variable $^{1}$ & Estimate & SE & $P$-value \\
\hline Calving to first service $(\mathrm{n}=88,633)$ & & & \\
High LNSCC before first breeding & 21.8 & 0.39 & $<0.0001$ \\
Calving year & -0.13 & 0.06 & 0.042 \\
Calving season & 0.72 & 0.16 & $<0.0001$ \\
Lactation number & -8.94 & 0.37 & $<0.0001$ \\
Herd MY 305ME & -1.02 & 0.23 & $<0.0001$ \\
Milkings/day, $\mathrm{n}$ & 4.15 & 0.62 & $<0.0001$ \\
Calving to conception (n= 70,877) & 48.7 & 0.84 & $<0.0001$ \\
High LNSCC before fertile breeding & 9.84 & 0.69 & $<0.0001$ \\
MY 305 & 0.62 & 0.19 & 0.0011 \\
Calving year & 1.66 & 0.37 & $<0.0001$ \\
Calving season & -14.56 & 0.85 & $<0.0001$ \\
Lactation number & -2.50 & 0.67 & 0.0002 \\
Herd MY 305ME & 7.31 & 1.43 & $<0.0001$ \\
Milkings/day, $\mathrm{n}$ & & & \\
Services per conception (n=70,877) & 0.49 & 0.012 & $<0.0001$ \\
High LNSCC before fertile breeding & 0.17 & 0.007 & $<0.0001$ \\
MY 305 & -0.05 & 0.011 & $<0.0001$ \\
Lactation number & & & \\
\hline
\end{tabular}

${ }^{1}$ High LNSCC $=$ SCC log linear score $\geq 4.5$; calving year: 1997-2006; calving season: 4 levels; lactation number: 1 vs. $\geq 2$; MY $305=$ milk yield standardized to $305 \mathrm{~d}(1=$ low, $2=$ medium, $3=$ high $)$; MY $305 \mathrm{ME}=$ milk yield standardized to $305 \mathrm{~d}$ and mature equivalent $(1=$ low, $2=$ medium, $3=$ high $)$; milkings/day: 2 vs. 3 .

for clinical and subclinical mastitis. In contrast, Klaas et al. (2004) reported an increase in CFSI for cows affected by subclinical mastitis $(11.7 \mathrm{~d})$, but not for clinical cases. They reported that clinical and subclinical mastitis did not increase days open.

\section{Conception at First Service}

Results of logistic regression for CFS are in Table 2. The percentage of CFS was $47.8 \%$. Results for the logistic regression models indicated that following a first service, the odds of conception for cows that registered a high LNSCC $(\geq 4.5)$ within the $30 \mathrm{~d}$ before the breeding were 0.85 [0.81 to $0.89 ; 95 \%$ confidence interval (CI)] times the odds of conception for cows without a high LNSCC. A similar effect occurred for high LNSCC after breeding; cows that registered a high LNSCC $(\geq 4.5)$ within $30 \mathrm{~d}$ after breeding reduced their odds of conception at first service to 0.82 (0.78 to 0.87 ; $95 \%$ CI), the odds of cows without a high LNSCC.

An effect of mastitis on CFS was reported by Santos et al. (2004) with a decreased value for cows affected by clinical mastitis before the first service postpartum. Loeffler et al. (1999) reported a difference in raw percentage of pregnancy between cows with mastitis after breeding and the remaining cows (29 vs. $45 \%$ ). In contrast to our results, these authors did not find a difference when the mastitis episode was 20 to $40 \mathrm{~d}$ before breeding.

\section{Survival Analysis for Risk of Pregnancy}

Figure 1 provides survival curves for the risk of nonpregnancy stratified by presence or not of a high LNSCC $(\geq 4.5)$ before conception. Results for the Cox

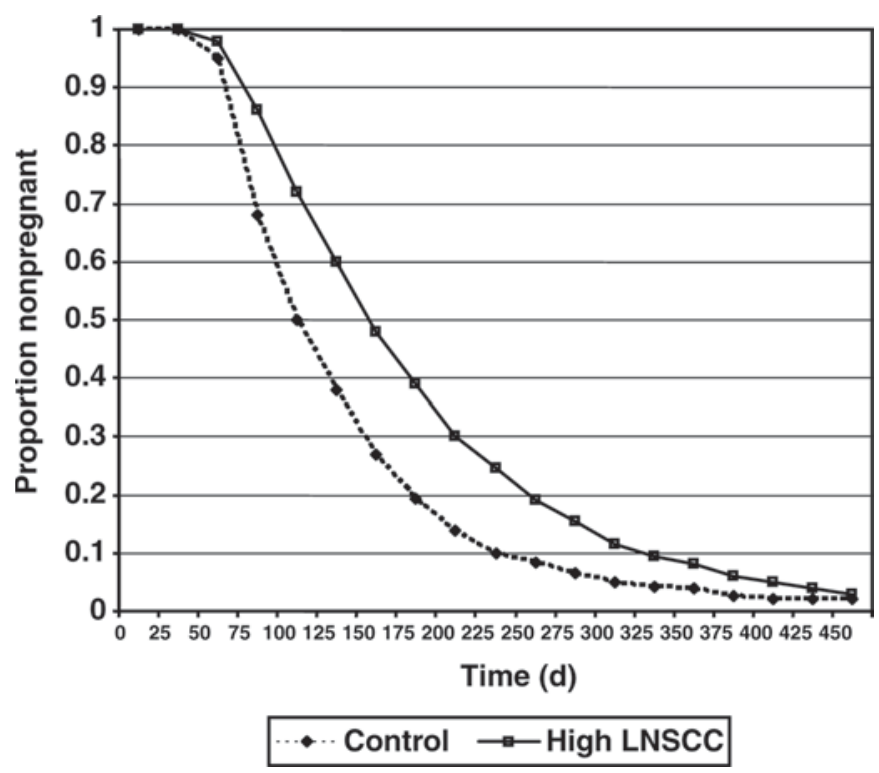

Figure 1. Survival curves for the interval from calving to conception in control cows (SCC log linear score $<4.5)$ and cows with a high SCC log linear score (LNSCC $\geq 4.5$ ) before a fertile service. Least squares means for days to conception for controls and cows with high LNSCC were 120.6 and $169.3 \mathrm{~d}$, respectively. 
Table 2. Logistic regression model for conception at first service as affected by a high SCC log linear score (LNSCC $\geq 4.5)$ before and after $( \pm 30$ d) breeding (only significant effects are included; $P \leq 0.05$ )

\begin{tabular}{lcc}
\hline Variable $^{1}$ & Odds ratio & $95 \% \mathrm{CI}^{2}$ \\
\hline High LNSCC before $(30 \mathrm{~d})$ breeding & & \\
High LNSCC & 1 & $0.81-0.89$ \\
No (reference) & 0.77 & $0.76-0.80$ \\
Yes & 0.90 & $0.87-0.94$ \\
MY 305 & & $0.78-0.87$ \\
Lactation number & 1 & $0.76-0.80$ \\
High LNSCC after (30 d) breeding & 0.82 & $0.87-0.94$ \\
High LNSCC & 0.77 & \\
No (reference) & 0.90 & \\
Yes & & $0.79-0.86$ \\
MY 305 & 1 & $0.76-0.80$ \\
Lactation number & & $0.83-0.94$ \\
High LNSCC before, before, after, or concurrent $( \pm 30$ d) with breeding & 0.77 \\
High LNSCC & 0.91 & \\
No (reference) & & \\
Yes & & \\
Lactation number & & \\
\hline
\end{tabular}

${ }^{1} \mathrm{LNSCC}=\mathrm{SCC} \log$ linear score; MY $305=$ milk yield standardized to $305 \mathrm{~d}(1=$ low, $2=$ medium, $3=$ high $)$; lactation number: 1 vs. $\geq 2$.

${ }^{2} \mathrm{CI}=$ confidence interval.

proportional hazard model indicated that after controlling for calving year, lactation number and milk yield standardized to $305 \mathrm{~d}$, the risk of pregnancy decreased by $44 \%$ if a high LNSCC occurred before conception $(P$ $\leq 0.001$ ). Risk of pregnancy was lower when milk yield was higher. On the other hand, risk of pregnancy was slightly higher with later calving years and second and greater lactation number (Table 3 ).

\section{Risk of Abortion}

Prevalence of abortion during the period of analysis was $2.6 \%$. The information for this analysis was derived from several herds in which veterinarians applied different methods for pregnancy diagnosis. Differences in opportunity for diagnosis (time after breeding) as well as diverse sensitivities of these methods may have limited the ability to detect abortion. Given that a proportion of pregnancy loss occurs early in gestation (Pursley et al., 1998; Lucy, 2001), the later a diagnosis of pregnancy is performed, the higher the proportion of abortions that are undetected. This consideration could explain the low prevalence of abortion during the period of analysis.

Results for logistic regression for abortion occurrence are in Table 4 . The proposed logistic regression models for risk of abortion indicated that, after controlling for potential confounding variables, cows experiencing a high LNSCC $(\geq 4.5)$ during the first $90 \mathrm{~d}$ of gestation had an increased risk of abortion. This group was 1.22 (1.07 to $1.35 ; 95 \%$ CI) times more likely to undergo an abortion than cows without a high LNSCC. The odds of abortion increased with the number of infertile breedings before conception and decreased with year of calving and lactation number.

The effect found in this study supports the incidence of abortions for cows affected by clinical mastitis. Santos et al. (2004) reported an increased incidence of abortions in cows experiencing clinical mastitis at any time during the lactation when compared with control cows. Risco et al. (1999) found that cows that had clinical mastitis during the first $45 \mathrm{~d}$ of gestation were at 2.7 times higher risk of abortion within the next $90 \mathrm{~d}$ than cows without mastitis. Chebel et al. (2004) reported that cows diagnosed with clinical mastitis during the first $45 \mathrm{~d}$ after breeding experienced increased pregnancy loss (odds ratio $=2.8 ; 95 \%$ CI: 1.16 to 6.78 ). We support the findings of Moore et al. (2005) where cows with a linear SCS $>4.5$ before breeding were twice as likely to lose their embryo by 35 to $41 \mathrm{~d}$ compared with cows with a score $<4.5$.

The study considered a large number of lactation records from a specific dairy region located in Chile. Extrapolation of results to other cow populations may

Table 3. Cox proportional regression model for the risk of pregnancy in central-southern Holstein Chilean cattle (only significant effects are included; $P \leq 0.05)$

\begin{tabular}{lccl}
\hline Variable $^{1}$ & Hazard ratio & $\mathrm{SE}$ & $P$-value \\
\hline High LNSCC & 0.56 & 0.01 & $<0.0001$ \\
MY 305 & 0.88 & 0.006 & $<0.0001$ \\
Calving year & 1.01 & 0.002 & $<0.04$ \\
Lactation number & 1.08 & 0.01 & $<0.0001$ \\
\hline
\end{tabular}

${ }^{1}$ High LNSCC $=$ SCC $\log$ linear score $>4.5$; MY $305=$ milk yield standardized to $305 \mathrm{~d}$ ( $1=$ low, $2=$ medium, $3=$ high $)$; calving year: 1997-2006; lactation number: 1 vs. $\geq 2$. 
Table 4. Logistic regression model for abortion risk as affected by a high LNSCC during the first $90 \mathrm{~d}$ of gestation (only significant effects are included; $P \leq 0.05$ )

\begin{tabular}{lcl}
\hline Variable $^{1}$ & Odds ratio & $95 \% \mathrm{CI}^{2}$ \\
\hline High LNSCC & 1 & \\
No & 1.22 & $1.07-1.35$ \\
Yes & 0.974 & $0.94-0.99$ \\
Calving year & 0.83 & $0.742-0.93$ \\
Lactation number & 1.71 & $1.66-1.77$ \\
Service number &
\end{tabular}

${ }^{1}$ High LNSCC $=$ SCC $\log$ linear score $\geq 4.5$; calving year: 1997-2006; lactation number: 1 vs. $\geq 2$.

${ }^{2} \mathrm{CI}=$ confidence interval.

not be valid because of different management scenarios and environmental conditions.

\section{CONCLUSIONS}

Subclinical mastitis, measured by an LNSCC $\geq 4.5$, had a significant impact on reproductive performance in Chilean dairy cattle, manifested by increased CFSI, CCI, and SC. High LNSCC in the proximity of first breedings had a detrimental effect on conception. The odds of occurrence of abortion for cows with high LNSCC during the first $90 \mathrm{~d}$ of gestation were increased by 1.22 times compared with unaffected cows.

\section{ACKNOWLEDGMENTS}

The authors thank Insecabio Ltda. (Los Angeles, Chile) for graciously providing the database analyzed in the present study.

\section{REFERENCES}

Bar, D., Y. T. Grohn, G. Bennett, R. N. Gonzalez, J. A. Hertl, H. F. Schulte, L. W. Tauer, F. L. Welcome, and Y. H. Schukken. 2007. Effect of repeated episodes of generic clinical mastitis on milk yield in dairy cows. J. Dairy Sci. 90:4643-4653.

Barker, A. R., F. N. Schrick, M. J. Lewis, H. H. Dowlen, and S. P. Oliver. 1998. Influence of clinical mastitis during early lactation on reproductive performance of Jersey cows. J. Dairy Sci. 81:12851290.

Bradley, A. J. 2002. Bovine mastitis: An evolving disease. Vet. J. 164:116-128.

Chebel, R. C., J. E. Santos, J. P. Reynolds, R. L. Cerri, S. O. Juchem, and M. Overton. 2004. Factors affecting conception rate after artificial insemination and pregnancy loss in lactating dairy cows. Anim. Reprod. Sci. 84:239-255.

Gilbert, R. O., W. T. K. Bosu, and A. T. Peter. 1990. The effect of Escherichia coli endotoxin on luteal function in Holstein heifers. Theriogenology 33:645-651.

Giri, S. N., Z. Chen, E. J. Carroll, R. Mueller, M. J. Schiedt, and L. Panico. 1984. Role of prostaglandins in the pathogenesis of bovine mastitis induced by Escherichia coli endotoxin. Am. J. Vet. Res. 45:586-591.

Giri, S. N., P. Emau, J. S. Cullor, G. H. Stabenfeldt, M. L. Bruss, R. H. Bondurant, and B. I. Osborne. 1990. Effect of endotoxin on circulating levels of eicosanoids progesterone, cortisol, glucose and lactic acid, and abortion in pregnant cows. Vet. Microbiol. $21: 211-231$.

Hansen, P. J., P. Soto, and R. P. Natzke. 2004. Mastitis and fertility in cattle - Possible involvement of inflammation or immune activation in embryonic mortality. Am. J. Reprod. Immunol. 51:294-301.

Instituto Geográfico Militar. 2006. Atlas de la República de Chile. 4a Edición. Editorial IGM, Santiago, Chile.

Jackson, J. A., D. E. Shuster, W. J. Silvia, and R. J. Harmon. 1990 Physiological response to intramammary or intravenous treatment with endotoxin in lactating dairy cows. J. Dairy Sci. 73:627632 .

Keown, J. F., R. W. Everett, N. B. Empet, and L. H. Wadell. 1986. Lactation curves. J. Dairy Sci. 69:769-781.

Klaas, I. C., U. Wessels, H. Rothfuss, B. A. Tenhagen, W. Heuwieser, and E. Schallenberger. 2004. Factors affecting reproductive performance in German Holstein-Friesian cows with a special focus on postpartum mastitis. Livest. Prod. Sci. 86:233-238.

Kossaibati, M. A., and R. J. Esslemont. 1997. The costs of production diseases in dairy herds in England. Vet. J. 154:41-51.

Loeffler, S. H., M. J. Vries, and Y. H. Schukken. 1999. The effects of time of disease occurrence, milk yield, and body condition on fertility of dairy cows. J. Dairy Sci. 82:2589-2604.

Lucy, M. C. 2001. Reproductive loss in high-producing dairy cattle: Where will it end? J. Dairy Sci. 84:1277-1293.

Melendez, P., and P. Pinedo. 2007. The association between reproductive performance and milk yield in Chilean Holstein cattle. J. Dairy Sci. 90:184-192.

Miller, G. Y., P. C. Bartlett, S. E. Lance, S. Anderson, and L. E. Heider. 1993. Costs of clinical mastitis and mastitis prevention in dairy herds. J. Am. Vet. Med. Assoc. 202:1230-1236.

Miller, R. H., J. S. Clay, and H. D. Norman. 2001. Relationship of somatic cell score with fertility measures. J. Dairy Sci. 84:25432548 .

Moore, D. A., J. S. Cullor, R. H. Bondurant, and W. M. Sischo. 1991. Preliminary field evidence for the association of clinical mastitis with altered interestrus intervals in dairy cattle. Theriogenology $36: 257-265$.

Moore, D. A., M. W. Overton, R. C. Chebel, M. L. Truscott, and H. BonDurant. 2005. Evaluation of factors that affect embryonic loss in dairy cattle. J. Am. Vet. Med. Assoc. 226:1112-1118.

Pursley, J. R., R. W. Silcox, and M. C. Wiltbank. 1998. Effect of time of artificial insemination on pregnancy rates, calving rates, pregnancy loss, and gender ratio after synchronization of ovulation in lactating dairy cows. J. Dairy Sci. 81:2139-2144.

Rajala-Schultz, P. J., Y. T. Groöhn, C. E. McCulloch, and C. L. Guard. 1999. Effects of clinical mastitis on milk yield in dairy cows. J. Dairy Sci. 82:1213-1220.

Rekik, B., N. Ajili, H. Belhani, A. Ben Gara, and H. Rouissi. 2008. Effect of somatic cell count on milk and protein yields and female fertility in Tunisian Holstein dairy cows. Livest. Sci. 116:309317.

Risco, C. A., G. A. Donovan, and J. Hernandez. 1999. Clinical mastitis associated with abortion in dairy cows. J. Dairy Sci. 82:16841689

Santos, J. E. P., R. L. A. Cerri, M. A. Ballaou, G. E. Higginbotham, and J. H. Kirk. 2004. Effect of timing of first clinical mastitis occurrence on lactational and reproductive performance on Holstein dairy cows. Anim. Reprod. Sci. 80:31-45.

Schrick, F. N., M. E. Hockett, A. M. Saxton, M. J. Lewis, H. H Dowlen, and S. P. Oliver. 2001. Influence of subclinical mastitis during early lactation on reproductive parameters. J. Dairy Sci. 84:1407-1412.

Schrick, F. N., A. M. Saxton, M. J. Lewis, H. H. Dowlen, and S. P. Oliver. 1999. Effects of clinical and subclinical mastitis during early lactation on reproductive performance of Jersey cows. Pages 189-190 in Proc. Natl. Mastitis Council Ann. Mtg. Natl. Mastitis Counc., Madison, WI 